This is a post-refereeing final draft. When citing, please refer to the published version:

Cohen, S.A., Higham, J.E.S. and Cavaliere, C.T. (2011). Binge flying: Behavioural addiction and climate change. Annals of Tourism Research, 38(3), 1070-1089. DOI:

10.1016/j.annals.2011.01.013

\title{
BINGE FLYING:
}

Behavioural addiction and climate change

Scott A. Cohen ${ }^{\mathrm{a}}$

James E.S. Higham ${ }^{b}$

Christina T. Cavaliere ${ }^{\mathrm{b}}$

${ }^{a}$ corresponding author: School of Tourism, Bournemouth University, Dorset House, Talbot Campus, Poole, Dorset, BH12 5BB, United Kingdom. Tel: +44 1202 961261; Fax: +44 1202 515707; Email: scohen@bournemouth.ac.uk

${ }^{\mathrm{b}}$ Department of Tourism, School of Business, University of Otago, Dunedin, 9054, New Zealand. Tel: +64 3479 8520; Fax: +64 3479 9034; Emails: james.higham@otago.ac.nz; christina.cavaliere@otago.ac.nz

\begin{abstract}
Recent popular press suggests that 'binge flying' constitutes a new site of behavioural addiction. We theoretically appraise and empirically support this proposition through interviews with consumers in Norway and the United Kingdom conducted in 2009. Consistent findings from across two national contexts evidence a growing negative discourse towards frequent short-haul tourist air travel and illustrate strategies of guilt suppression and denial used to span a cognitive dissonance between the short-term personal benefits of tourism and the air travel's associated long-term consequences for climate change. Tensions between tourism consumption and changing social norms towards acceptable flying practice exemplify how this social group is beginning to (re)frame what constitutes 'excessive' holiday flying, despite concomitantly continuing their own frequent air travels.
\end{abstract}

Keywords: behavioural addiction, air travel, climate change, social norms 


\section{INTRODUCTION}

Within contemporary lifestyles that are characterised by increased freedom of choice, there is also the "freedom to become "addicted", to be emotionally and/or physically dependent upon excessive consumption of certain products of global capitalism' (Urry, 2010, pp. 93-94). Whilst the term 'addiction' is traditionally restricted to substance dependency, a number of behaviours are now being viewed as potentially addictive, including shopping, exercise, video games, overeating, gambling and sex (Clark \& Calleja, 2008; Griffiths, 1996). Recently, two articles in the popular press have further implicated frequent tourist air travel as a practice that may constitute behavioural addiction (Hill, 2007; Rosenthal, 2010). In stark contrast to most behavioural addictions, which are characterised by severe negative consequences for individuals directly, the destructive outcome attributable to excessive flying is premised upon air travel's growing contribution to global climate change.

Both Burns and Bibbings (2009) and Randles and Mander (2009a) cite Hill's (2007) interview in The Observer with Rough Guides founder Mark Ellingham, who coins the term 'binge flying' in critiquing the public's growing appetite for holidays accessed through air travel. Burns and Bibbings (2009, p. 34) interpret Ellingham's claim as 'the middle classes of the developed world are somehow addicted to carbon-intensive leisure mobility' and argue that the manifestation of the term binge flying epitomises the negative publicity pointed at excessive air travel. Ellingham extends his critique of the $\mathrm{CO}_{2}$ impacts of air travel by drawing parallels between the tourism and tobacco industries, claiming that the tobacco industry fouled up the world while denying [it] as much as possible for as long as they could... if the travel industry rosily goes ahead as it is doing, ignoring the effect that carbon emissions from flying are having on climate change, we are putting ourselves in a very similar position to the tobacco industry' (Hill, 2007, np). The analogy of tourism as 'the new tobacco' is taken further in Rosenthal's (2010, np) piece in the Guardian, where she approaches air travel through a lens of addiction, claiming that for many, both leisure and business are so dependent on flying that it 'has become as reflexive as hopping in the car'. This discourse of the addictive consumption of tourist air travel surfacing in the media is also emerging in the social sciences, as Urry (2010) observes that the excessive consumption of tourism is contributing to 'binge mobility'.

This article theoretically appraises the proposition that excessive tourist air travel, or binge flying, may constitute a new site of behavioural addiction, and offers supporting empirical evidence of changing consumer discourses towards the practice of holiday frequent flying. The paper is innovative in both its interdisciplinary analysis of binge flying as a subject of explicit focus and in its consideration of tourism consumption through a lens of behavioural addiction. The empirical material is based on in-depth interviews with consumers in Norway and the United Kingdom conducted in 2009. The study thus not only extends and deepens existing empirical work on the ways in which tourists are responding to air travel's 
climate impacts, but its comparative design also offers consistent findings from across two European national contexts.

Following Clark and Calleja (2008, p. 638), we do not seek to 'medicalise' a moral agenda by 'creating a new [behavioural] disorder', but rather analyse how and why social norms may be shifting so that frequent tourist air travel is beginning to be negatively valued in consumer discourses. Our discussion is framed by the literature on behavioural addiction, in which excessive behaviour is broadly conceptualised as offering particular psychological benefits to the consumer, as well as negative consequences (Clark \& Calleja, 2008; Elliott, 1994). As such, we consider the different ways in which tourist air travel has become socially embedded in sections of societies, and how these practices may produce tensions between the perceived personal and social benefits of tourism and climate change behavioural adaptation, a conflict Rosenthal (2010) describes as the 'flyers' dilemma'.

\section{TOURISM AIR TRAVEL BEHAVIOURAL ADDICTION}

As a socio-culturally constructed valuation, behavioural addiction is unavoidably a nebulous concept. One common element, however, is that behavioural addictions involve satisfying short-term pleasure at the expense of longer-term negative effects (Clark \& Calleja, 2008). Griffiths (1996) notes that behavioural addictions may have 'normative ambiguity', in that moderate use is accepted but stigma can result from over-enactment of the behaviour, or compulsive consumption (Hirschman, 1992). The constitution of 'excessive' or 'compulsive' consumption that lies in potential conflict with social norms is influenced by personal, economical, social and cultural factors (Clark \& Calleja, 2008). For example, Hirschman (1992, p. 156) outlines how drug use was not viewed as a social problem during the $18^{\text {th }}$ and $19^{\text {th }}$ centuries, however by the $20^{\text {th }}$ century it came to be seen as 'morally debasing', exemplifying that ' $[\mathrm{t}]$ he metaphors with which a society conceptualizes phenomena inevitably influences the social response to them'.

Three characteristics are identified as commonly appearing across addictive phenomena, including a drive or urge to engage in the particular behaviour, denial of the harmful consequences of the behaviour and failure in attempts to modify the behaviour (Faber, O'Guinn, \& Krych, 1987). Elliot (1994) observes that short-term effects tend to influence behaviour more than longer-term consequences, with some consequences being repressed or denied if thinking about them is too distressful. In Faber et al.'s (1987) seminal study of compulsive buyers, negative emotional states are found before and after buying binges, accompanied by denial patterns. In their later study of shopping addiction, Clark and Calleja (2008) report participants use shopping to achieve a desired 'heightened state' that they would knowingly continue despite negative consequences. Shopping functions for these individuals as a means of repairing mood and is accompanied by a preoccupation about shopping and advance ritualised acts of scanning the retail environment in search of potential purchases (Clark \& Calleja, 2008). 
Even though addictions are typically conceptualised as purely negative, Griffiths (1996) distinguishes a number of possible addiction benefits that individuals may perceive, such as changes of mood and feelings of escape, positive experiences of pleasure, excitement, relaxation, disinhibition of behaviour and the activity as a source of identity and/or meaning in life. Elliot (1994) takes this last benefit further by conceptualising the behaviour's capacity for mood regulation as a means of temporarily filling a vacuum of 'self' felt through the fragmentation of postmodernity. As such, 'ingesting' products allows for the momentary experience of one or more of many 'possible selves' (Elliott, 1994). Beyond personal attachment perspectives, which largely view behavioural addiction as stemming from unmet psychological needs, Clark and Calleja (2008) emphasise sociological models wherein addictive behaviour is socially learned through family, peers, media and subculture. In this latter sense, addictive behaviour can be understood not only from the psychological perspective of the cognitive and affective actor, but also as embedded and (re)produced in the practices of social institutions.

Unlike the example of shopping addiction, the long-range consequences of excessive tourist air travel reach far beyond the state of the consumer's wallet. Whereas most behavioural addictions imply negative consequences directly for the consumer, the impacts of excessive air travel are, both literally and figuratively, more dispersed. There is increasing pressure on the tourism industry to move to a sustainable emissions path (Gössling, 2009). Although the contribution of aviation to global $\mathrm{CO}_{2}$ emissions was approximately $3.5 \%$ in 2005 (Smith \& Rodger, 2009), rapid, unrestricted growth is forecast for the aviation industry that will result in it emitting 15-40\% of total global $\mathrm{CO}_{2}$ by 2050 (Dubois \& Ceron, 2006; Gössling \& Peeters, 2007). Tourism is currently directly accountable for $4.4 \%$ of global $\mathrm{CO}_{2}$ emissions (Peeters \& Dubois, 2010), with $40 \%$ of this figure conservatively attributed to tourist air travel (Gössling, 2009). To disentangle, however, tourist air travel from broader passenger air travel is a challenging proposition. Tourism is increasingly coupled (and even masked) with visiting friends and relatives and/or business, and has become essential for the many whose social connections are ever more networked or spatially 'stretched out' (Larsen, Urry, \& Axhausen, 2007).

In response to air travel's impact on accelerating global climate change, the academe is demonstrating sustained interest in the issue (e.g. Becken \& Hay, 2007; Dickinson, 2010; Gössling \& Upham, 2009). Burns and Bibbings (2009) observe that the 'deep problem' within the tourism supply and consumption chain is of such a scale that habits, social norms and practices associated with air travel must be challenged and changed as part of a global transition to low carbon economies. Based on work with contemporary scenario and backcasting techniques, Peeters and Dubois (2010) conclude that improvements in technology alone will be insufficient in developing a sustainable future tourist travel system and that 'radical shifts' will be needed. If the tourism industry is to adapt to a lower carbon future, major modal shifts in tourism transport combined with holidaying in destinations closer to home will be necessary (Dickinson, 2010). This is in stark contrast to current trends of travelling longer distances, shorter stays, more frequent departures and increasing flying (Ceron \& Dubois, 2007). Consequently, Dickinson (2010) calls for new methodologies in the 
field of tourism and climate change, which explore why and how particular tourist practices and conventional assumptions have arisen.

\section{Socially (dis)embedded tourist air travel}

A number of studies have focused on tourists' perceptions of and attitudes towards air travel and climate change (Becken, 2004; Cohen \& Higham, 2011; Hares, Dickinson, \& Wilkes, 2010; Higham \& Cohen, 2011; Shaw \& Thomas, 2006). Dickinson (2010) critiques this type of actor-centred approach and suggests the use of social practice theory may be more effective at tackling the deeply embedded practice of tourist air travel. This stems from the observation that attitudes do not necessarily translate into specific behaviour in certain structured contexts (Verbeek \& Mommaas, 2008). With its focus on practice, social practice theory considers the interrelations between individual agency and wider societal structural and technological factors (Dickinson, Robbins, \& Lumsdon, 2010), and moves away from actor-structure dualism (Verbeek \& Mommaas, 2008). Verbeek and Mommaas (2008, p. 634) define social practices as 'historically shaped, concrete interaction points between, on the one hand actors, with their lifestyles and routines, and on the other hand, modes of provision with their infrastructures of rules and resources, including norms and values.' Whilst we do not endeavour here a thorough discussion or application of social practice theory (for this see Reckwitz, 2002; Verbeek \& Mommaas, 2008; Warde, 2005), there exist a handful of key studies that do consider why and how particular tourist air travel practices have arisen (Burns \& Bibbings, 2009; Randles \& Mander, 2009a, 2009b; Urry, 2010), which fruitfully inform our analysis of frequent tourist air travel as a site of potential behavioural addiction.

One of the key reasons that air travel has become embedded in (and will be difficult to disembed from) holiday practices is that the ideal of freedom is firmly established in the minds of many tourists (Becken, 2007). This sense of freedom to travel has been coconstructed through the rapid expansion of low-cost airlines (Shaw \& Thomas, 2006), which is one way in which unbridled capitalism has generated new forms of excessive consumption (Urry, 2010). Burns and Bibbings (2009, pp. 31-32) note how tourist practice is in direct conflict with the 'mega-crisis' of climate change due to 'ubiquitous and commodified leisure mobility brought about by cheap (and even "free") air flights', which have become available due to tax breaks on aviation fuel, air traffic deregulation, intense corporate competition, savvy destination marketing, the capacity for Internet booking and increased wealth. Two low-cost carriers alone, Ryanair and easyJet, supply an extra 30 million return seats per year (Burns \& Bibbings, 2009). Despite the claims of low-cost airlines to have made flying more accessible to poorer groups, frequent flying is still primarily the preserve of higher income and higher social class groups (Randles \& Mander, 2009b).

The excessive consumption of air travel is not limited to shorter-range travel, however, as Burns and Bibbings (2009, p.39) highlight that 'cash-rich and time-poor consumers' are also enticed into more frequent long-range air travel through practices such as 'weekend shopping trips to Dubai or New York; weekend safari trips in Kenya; city breaks in China or South Africa'. Observing the excessive consumption of holidays as amplifying 
mobility, and as we argue, as a potential site of behavioural addiction, Urry (2010, pp. 90-91) cites increasing performances of people touring the world as 'connoisseurs and collectors of places', such as those boasting attractions of 'good beaches, clubs, views, walks, mountains, unique history, surf, music scene, historic remains, sources of good jobs, food, landmark buildings, gay scene, party atmosphere, universities and so on'. Burns (2005) offers the term 'trophy tourism', which he describes as the tendency for tourists to 'tick off' destinations to add to a de-contextualised collection. Randles and Mander (2009b) note that this phenomenon may involve only visiting a destination for a couple of days before adding it to one's mental list, with length or depth of experience unimportant.

Consuming and collecting holiday experiences, for the rich third of the world, is linked to increased freedom from certain structures, which results in friends, partners and family that are more a matter of choice and progressively more spread around the world (Urry, 2010). Consequently, flying has moved from an extraordinary event to the domain of the everyday as a 'locked-in' social institution (Randles \& Mander, 2009a), wherein people 'extend and elaborate their consumption patterns' as part of developing personalised life projects (Urry, 2010, p. 90). Illustrating how air travel is being embedded in celebrations, events and occasions that would have previously been performed locally, Randles and Mander (2009a, p. 245) 'find that for certain identified groups in society, flying now forms an integral part of celebrating a birthday, anniversary or retirement, taking a city break, relaxing and getting away from it all, visiting friends and family, or pursuing a special interest'. Larsen, Urry and Axhausen (2007, p. 255) illustrate how low-cost airlines 'can assemble dispersed social networks', in places such as Berlin, Amsterdam and Prague (e.g. for hen and stag nights) 'at a cost that is little more than the cost of meeting up within the United Kingdom'. Earlier commentary on the hyperconsumption of air travel argues that any regulations that may limit these corporeal mobilities would generate exclusion and weaken social capital (Urry, 2002). Randles and Mander (2009a) do distinguish, however, a growing level of dissonance between the practice of frequent flying and how it is beginning to be perceived by some parts of the public as socially unacceptable.

\section{Tensions in excessive air travel consumption}

There is increasing tension in both academic and popular discourse between the social and personal benefits of flying and air travel's impact on climate change, which is succinctly termed 'flyers' dilemma' in the public press (Rosenthal, 2010). Randles and Mander (2009a, p. 270) explain that this conundrum leaves individuals to reconcile what it now means to be a 'good citizen', as 'we appear to be on a cusp between the ratcheting standards inducing frequent flying on the one hand and a "tipping" of popular discourse against flying for environmental and climate change concerns on the other'. This is evidenced in the academic literature by recent studies that present seemingly contradictory evidence on the subject. Whereas Miller, Rathouse, Scarles, Holmes and Tribe (2010) find public reluctance in the United Kingdom to engage in sustainable tourism through taking fewer holidays, Cohen and 
Higham (2011) report a growing movement of British consumers who are beginning to consume air travel with a 'carbon conscience'.

A growing carbon conscience over tourist air travel may be located within a wider trend in lifestyle factors associated with ethical consumerism. Burns and Bibbings (2009) cite Siegle's (2005) article in The Observer that locates a new social movement being segmented by marketers, referred to as the 'New Puritans'. New Puritans are described as a growing movement of youngish and mostly educated individuals who are reacting against 'unethical' consumption on a number of levels, including, amongst others, $4 \times 4$ use in cities, processed food in schools, 'unfair' trade, and increasingly, air travel (Siegle, 2005). The repercussions of the extension of New Puritan values into social norms is alluded to by Ryan (2010, p. 38) who explains how social norms can shift as consumption patterns change: 'If people were to view their holiday-taking behaviour as involving anti-social actions, then the holiday and travel related industries as we know them would be forced to change... Social attitudes do not change overnight, but can and do change over a matter of a few decades.'

Despite the social movement of New Puritanism and evidence of increasing consumer concern over air travel emissions, there is a manifest reluctance for individuals to actually adjust their tourism air travel practices on a significant scale. Even individuals that may be committed to environmental practices at home (e.g. reducing waste and energy use, buying organic, 'ethical' purchasing) are often unwilling to reduce holiday air travel (Barr, Shaw, Coles, \& Prillwitz, 2010). This insatiable appetite for consuming tourism experiences made available through air travel appears socially 'locked-in', with the short-term social and personal benefits of tourism largely privileged despite longer-term knock-on effects for global climate change.

Not only does excessive tourist air travel meet this basic criterion of behavioural addiction where longer-term outlooks are sacrificed for immediate gratification, but tourist experiences also supply many of the psychological benefits that Griffiths (1996) uses to characterise sites of potential behavioural addiction. These include feelings of escape, heightened experiences of pleasure and excitement (a 'buzz' or 'rush'), relaxation, disinhibition of behaviour and the activity as an arena for identity work and searching for meaning in life (Cary, 2004; Rojek, 1993; Ryan, 2010). Even the anticipation period between planning and the actual time spent on holiday is documented as providing personal gratification. For instance, in Randles and Mander's (2009a) interviews with frequent flyers, several participants describe planning, purchasing and preparing for an impending holiday as heightened pleasurable activity, often undertaken with a friend over a drink as a means of cheering up oneself. This may also be viewed as a form of 'cognitive narrowing', wherein attention is narrowed on more immediate pleasurable experiences as a means of overcoming negative emotions (Elliot, 1994). These same tourism experiences are then reportedly followed by a dip in spirits, or low, on return from their holidays, which functions as a habitual trigger towards planning their next trip (Randles \& Mander, 2009a). 
Examinations of shopping behavioural addiction report similar ritualised acts of preoccupation and planning, as well as the rise and fall in affective states that typically accompany buying binges (Clark \& Calleja, 2008; Faber et al., 1987). These shopping binges are often associated with denial patterns, with the impacts of air travel also reportedly embedded with a 'psychology of denial' (Gössling \& Peeters, 2007; Stoll-Kleemann, O'Riordan \& Jaeger, 2001). In situations where we are unable to change our behaviour, more information on a subject can lead to cognitive dissonance, which can result in a state of denial (Miller et al., 2010). Personal attachment to holidays can be so high that, despite awareness of air travel's climate impacts, many individual invoke a range of 'denial mechanisms' for why responsibility lies with others (Hares et al., 2010).

Any guilt that one may experience in deciding to fly, however, may be abandoned in arriving at a busy airport, where the social norm there is clearly one of aeromobility (Miller et al., 2010). Interestingly, one solution Miller et al. (2010) proffer towards fostering more proenvironmental flying behaviour is to recommend group support to individuals who seek to rein in their tourism habits, specifically citing the example of the 'weight-watchers' programme. The need for a 'self-help group' is identified as yet another culturally common feature of problem-inducing excessive behaviours (Walker \& Lidz, 1983). With parallels between holiday air travel and other sites of potential behavioural addiction, as well as media and academic voices that increasingly reflect negative valuations of 'excessive' flying, there is a clear need to empirically gauge 'on the ground' whether consumer discourses towards the practice of frequent tourist air travel are also shifting.

\section{Study methodology}

The empirical material presented in this paper is part of a wider study on climate change concern and air travel in European consumer markets. The study employs an interpretive research paradigm and is located within a relativist ontology (Denzin \& Lincoln, 2005). Whilst our research approach was non-activist and sought to elicit subjective perspectives on the subject area, we do hold the shared position that aviation $\mathrm{CO}_{2}$ emissions are a significant contributor to global climate change that need to be mitigated through both consumer behavioural adaptation and political and technical innovation. The qualitative materials consist of 30 semi-structured open-ended interviews conducted in Norway and the United Kingdom in 2009. Our interest in Norway and the United Kingdom arises from tensions between the conspicuous aeromobility of large sections of their respective populations and government initiatives aimed at climate change mitigation (Gössling, 2009; Hares et al., 2010; Høyer, 2000).

We chose the method of one-to-one open-ended interviewing for its flexibility in exploring issues in detail as they arise (Jennings, 2001) and because it reduces the influence of group norms on individual voices (Patton, 2002). The interview programme sought to address participant opinions on climate change and engage participants in a discussion of potential climate change concerns as they relate to day-to-day domestic behaviour, air travel 
behaviour and attitudes towards short, medium and long-haul air travel. The present paper draws its empirical material primarily from the participants' general perceptions towards their own air travel behaviour and the wider climate impact of flying, with a focus on shorter-haul tourist air travel, as a strong negative discourse towards this type of frequent flying emerged in the interviews. Although we advised participants that the interviews were non-activist, there may be a degree of interviewee bias resulting in dissonance between professed climate concern and any actual steps to rein in air travel behaviour. This may be particularly relevant in the context of high individual $\mathrm{CO}_{2}$ emissions, where presenting an account of hyperconsumption may be feared as socially undesirable.

Interviews were carried out first in Stavanger, Norway (15 participants) and immediately after in Bournemouth, United Kingdom (15 participants), when the lead author was based as a visiting researcher at both The University of Stavanger and Bournemouth University. Participants in both locations were recruited using a snowball sampling technique. Access to potential participants relied initially on key informants in each location, both from within and outside of the university contexts. Whilst the only selection criteria were that the participants self-identify as Norwegian or British nationals, respectively, and be willing to be interviewed face-to-face in English, we did aim to access a relatively equal gender distribution across a broad age range (minimum age 18 years). Interviews were conducted at neutral sites and were digitally recorded, with each lasting 30 to 60 minutes. The interviews produced a series of complex one-to-one human interactions (Fontana \& Frey, 2005), with evidence of saturation in the later stages of the interview programmes.

The interview participants included 15 females and 15 males with ages that ranged from 18 to 67 (Table 1). Their occupations reflected 12 industry professionals, six university academics, five university administrators, four postgraduate students, two undergraduate students and one retiree. The participants represented a range of education levels, but the majority were highly educated and moderately affluent, reflecting the research sample being driven out a university context. Although the participants were largely highly educated professionals, this social group is particularly important to study when considering air travel through a lens of behavioural addiction. It is this small sub-set of the total population in Europe who often have geographically stretched social relations, who may have to fly regularly for business and who, typically, have the necessary affluence to choose whether to use the low cost air model regularly for leisure practices. So while our collective participant profile reflects the attitudes and perceptions of potentially hypermobile individuals with the resources likely to give relevance to the notion of facing a 'flyers' dilemma', the perspectives presented here do not, on the other hand, give voice to sections of British or Norwegian society of lesser privilege. Our programme of in-depth interviews thus cannot be considered to represent either British or Norwegian society as a whole. 
Table 1

Summary profile of interview programme participants

\begin{tabular}{|c|c|c|c|c|c|}
\hline Pseudonym & Gender & Age & Nationality & Occupation & Highest qualification \\
\hline Frode & $\mathrm{M}$ & 37 & Norwegian & Industry professional & Masters \\
\hline Rita & $\mathrm{F}$ & 34 & Norwegian & Industry professional & Masters \\
\hline Bjørn & M & 41 & Norwegian & Industry professional & $\mathrm{PhD}$ \\
\hline Silje & $\mathrm{F}$ & 45 & Norwegian & Industry professional & Masters \\
\hline Svein & M & 35 & Norwegian & Industry professional & High school \\
\hline Tone & $\mathrm{F}$ & 58 & Norwegian & Postgraduate student & Masters \\
\hline Ida & $\mathrm{F}$ & 52 & Norwegian & University administrator & Masters \\
\hline Grete & $\mathrm{F}$ & 27 & Norwegian & Postgraduate student & Undergraduate \\
\hline Lars & M & 53 & Norwegian & Academic & $\mathrm{PhD}$ \\
\hline Pål & M & 34 & Norwegian & Industry professional & Masters \\
\hline Hilda & $\mathrm{F}$ & 67 & Norwegian & Retiree & Masters \\
\hline Håkon & M & 48 & Norwegian & Industry professional & Undergraduate \\
\hline Johannes & M & 57 & Norwegian & Academic & $\mathrm{PhD}$ \\
\hline Anette & $\mathrm{F}$ & 35 & Norwegian & Industry professional & Masters \\
\hline Grethe & $\mathrm{F}$ & 27 & Norwegian & Postgraduate student & Masters \\
\hline Cindy & $\mathrm{F}$ & 42 & British & University administrator & High school \\
\hline Jack & M & 35 & British & Industry professional & Undergraduate \\
\hline Grace & $\mathrm{F}$ & 36 & British & University administrator & Masters \\
\hline Jessica & $\mathrm{F}$ & 48 & British & University administrator & High school \\
\hline Ruby & $\mathrm{F}$ & 41 & British & Industry professional & High school \\
\hline Amy & $\mathrm{F}$ & 30 & British & Academic & $\mathrm{PhD}$ \\
\hline Hannah & $\mathrm{F}$ & 48 & British & Postgraduate student & Masters \\
\hline Oliver & M & 30 & British & Academic & Masters \\
\hline Thomas & M & 38 & British & Academic & Masters \\
\hline Harry & M & 40 & British & Industry professional & Undergraduate \\
\hline Daniel & M & 18 & British & Undergraduate student & High school \\
\hline Mia & $\mathrm{F}$ & 21 & British & Undergraduate student & High school \\
\hline James & M & 63 & British & Academic & $\mathrm{PhD}$ \\
\hline William & M & 42 & British & Industry professional & Undergraduate \\
\hline Lewis & M & 39 & British & Industry professional & Undergraduate \\
\hline
\end{tabular}

The findings do confirm that the participants were highly aeromobile themselves, as all were past and/or present regular flyers. International air travel at least once annually was routine among the participants, with several flights per year (and in some cases per month) not uncommon. This included domestic, short-haul intra-European and long-haul routings, for a mix of reasons spanning tourism, visiting friends and relatives and business. Whilst there was some evidence of reduced personal and business air travel in response to the 2008 global financial crisis, regular air travel remained the norm, reflecting the propensity of Europe's hypermobile to take multiple short-break holidays each year (Hares et al., 2010; Høyer, 2000). Participants in both countries expressed a common need for regular holidays in warm 
destinations. Following transcription and repeated readings of the interview transcripts, we independently applied a thematic analysis approach in formally interpreting the empirical material (Patton, 2002). This approach involved reducing the empirical material into categories guided by the participants' narratives without losing site of the research aims, a process which allowed for the identification of emergent themes (Miles \& Huberman, 1994; O'Reilly, 2005). After triangulating our respective individual interpretations from this blinded process, further joint discussion facilitated the development of the interpretations that follow.

\section{Changing consumer discourses towards frequent tourist air travel}

The study found significant evidence of shifting consumer discourses amongst participants in Norway and the United Kingdom towards negative valuations of frequent tourist air travel, most commonly associated with the use of low-cost airlines. This finding supports and empirically amplifies Randles and Manders' (2009a) observation that there are 'flickerings' of evidence of consumer environmental concern over air travel. Climate concern was coupled, however, with tensions in the participant's narratives over the consequences of their own air travel practices. While these findings were remarkably consistent in both Norway and the United Kingdom, the nationalities did diverge in their attitudes towards external mitigation through policy and other government initiatives, a topic which is beyond the scope of the current paper.

Participants in both countries cited air travel as deeply entrenched in their respective societies. As Håkon (Norwegian, 48) observed: 'We are heavy users of the airplane, we Norwegians. The planes more or less queue up between Stavanger and Oslo.' Silje (Norwegian, 45) described air travel as habitual practice in Norway that had become socioculturally engrained, despite widespread awareness of air travel's climate impact. 'I know it matters, but I still do travel. I'm a typical Norwegian in this way of thinking. So it's cultural the way of behaviour - we have the money, we have started travelling and would like to see more.' In the context of the United Kingdom, Mia (British, 21) was unable to disentangle air travel from the notion of taking a holiday and consequently viewed tourist air travel as an embedded way of life.

I think growing up in England, obviously dependent on how much money you've got; I think it's just a bit of a way of life now that maybe once a year you go to Spain or something. I don't think I could never fly again because then I'd never really have any holidays again.

While participants in both countries largely held annual holidays (often relying on air travel to reach warmer climates) as sacrosanct, frequent intra-European tourist air travel was, in contrast, commonly viewed with disapproval.

It's absolutely fine if people want to have an annual holiday, but the people who are flying ten times a year, including nearly six weekend trips to Prague and 
Budapest and what have you, I think that that's irresponsible behaviour (Oliver, British, 30).

Oliver helps fuel a changing public discourse towards the excessive use of low-cost airlines. Hannah (British, 48) extended the view that short-haul tourist binge flying is unacceptable behaviour due to its clear association with climate change.

We're overproducing, and because we're overproducing we're over consuming. A lot of people think, oh I've got nothing to do this weekend, I'll just see what flights are available and just jump on a plane to go somewhere. It would not upset me if that all fell apart, that part of travel.

Similar widely held views were expressed in the Norwegian case, again implicating the frequent use of low-cost airlines for intra-European tourist travel.

I don't think it's a very good thing the habit that Norwegians have had for a few years after we became very rich that we can, oh, weekend trip to Amsterdam, weekend trip to Prague, weekend trip to anywhere. Using a plane every weekend to go somewhere, it's not very sustainable. (Svein, Norwegian, 35)

Håkon took issue with current tourism trends of travelling longer distances, with more frequent departures and shorter stays (Ceron \& Dubois, 2007), equating the temporality of this mode of 'trophy tourism' (Burns, 2005) with a lack of depth that does not justify its $\mathrm{CO}_{2}$ emissions.

The trend is that you go on weekends to distant shores, and that is to me craziness. You go to a place and you spend a lot of money and pollute a lot and then you stay there just a short little while and then you go back again. It's useless - I did that as a businessman. (Håkon, Norwegian, 48)

These findings add complexity to those of Hares et al. (2010), who report an affinity between their study participants and low-cost airlines, citing the view that low-cost airlines opened up air travel to the masses. Although the ideal of equitably distributed and moderate usage of low-cost airlines is still socially sanctioned, the increasingly common practice of frequent low-cost flying by the mobile elite is seemingly not.

The views expressed here thus provide evidence that climate concern is contributing to normative ambiguity in what constitutes acceptable levels and forms of tourist air travel, as opposed to an excessive consumption that is subject to stigmatisation. Confirming Ryan's (2010, p. 38) observation that 'social consumption patterns can and do change', especially if one perceives their consumption as 'involving anti-social actions', the social norms of air travel consumption are already shifting within this section of society. Ironically though, while the participants here comfortably took aim at the frequent short-haul air travel practices of others, some of the study's more aeromobile participants denied and/or suppressed the consequences of their own air travel behaviour. 
Several participants expressed concern over air travel's climate consequences, but were unwilling to rein in their own appetites for tourism experiences. Instead, they used strategies of denial and guilt suppression in order to justify continued frequent holiday flying practices and its perceived personal benefits. In Thomas's (British, 38) case, his guilt associated with air travel emissions were no match for his intense desire to temporarily escape the United Kingdom each year.

I'm still going to want to go to Australia every year. I guess there's a certain sense of guilt there, but I kind of ignore that because I know that this is my leisure trip, this is my holiday and I want to go on that holiday.

For others, the tension between the short-term gratification associated with tourism and air travel's climate consequences were of a more severe nature.

To be honest, I don't dare to think about it. Because then I have to say to myself - 'why are you travelling so much?' But I like it - that's why it was very easy to buy this [voluntary carbon offset]. I said 'ok, I have done that, so now I can travel.' But inside, I'm not feeling good, because I am thinking of it and I have kids. (Ida, Norwegian, 52)

Ida suppressed the guilt she felt for how her present air travels might impact the future world her children will inherit. One common coping strategy she used was to voluntarily offset her air travel emissions with a carbon offsetting scheme.

Although analysis suggests that it is environmentally better to offset than to not (Broderick, 2009), voluntary carbon offsets are identified as at best 'a temporary or complementary strategy', which unfortunately carry the added risk of 'encouraging people to believe they need not change their [air travel] behaviour' (Gössling et al., 2007, p. 241). Illustrative of this risk, when asked her opinion of voluntary offsetting, Ruby (British, 41), who expressed a strong desire to see more of the world despite awareness of air travel's carbon impacts, beamed 'Oh, I would do that! I would do that happily. That would be great. It makes you feel better, doesn't it?' Other participants approached offsetting more cynically, describing it variably as a mechanism for buying good conscience, a means of offsetting guilt, or in the puritanical sense conveyed by Grethe (Norwegian, 27) - 'like the old religion thing where you sinned and could pay it off'. The most scathing review of this practice was offered by Jack (British, 35), who paralleled voluntary offsetting to 'punching somebody in the face and saying sorry afterwards...an excuse for people to not have to think about their own impacts and ignore what is going on with the climate'. Despite this negative discourse towards voluntary offsetting, the practice offers a potentially potent psychological strategy for suppressing guilt associated with air travel impacts. 
Consistent with previous studies (Barr et al., 2010; Gössling \& Peeters, 2007; Hares et al., 2010), guilt suppression strategies were accompanied by denial mechanisms aimed at placing the onus of responsibility for managing carbon impacts on other parties.

You know it's problematic and I should be concerned more but my conscience is not bad because of taking the shorter flights or taking the flights at all. I'm maybe putting the responsibility to the government instead of thinking that my own little contribution would mean a difference. But that is maybe a way to comfort myself in knowing that I'm actually flying myself. (Rita, Norwegian, 34)

Patterns of denial and suppression of guilt often arise in situations where we are unable to change or control our behaviour, effectively functioning as coping strategies for states of cognitive dissonance (Miller et al., 2010). Barr et al. (2010, p. 479) further suggest that denial may take place 'when the personal cost of such changes are perceived to be over-bearing'. Evidence of reluctance to sacrifice tourism's personal benefits while denying and suppressing responsibility for the harmful long-term climate consequences of tourist air travel further supports frequent holiday flying as a site of behavioural addiction.

\section{Modifying tourist air travel practice}

Alongside the drive or urge to engage in a particular behaviour and the denial of its harmful longer-term consequences, addictive phenomena are characterised by failures in attempts to modify the behaviour (Faber et al., 1987; Hirschman, 1992). As social networks and tourism destination lists expand, manifesting in opportunities to fly year-round and at lower costs, controlling the growing public appetite for air travel is increasingly problematic. Ruby (British, 41) described how the freedoms afforded through air travel are too exciting for individuals to control their own behaviour for the sake of climate change.

I think society now has got used to travelling. To take that away, it's almost as if it has to be taken away by somebody else, by governments, because it's too exciting for an individual to take it away. A lot of people fly quite a lot of the time.

Amy (British, 30) felt that any further government taxes on air travel, even an environmental tax, would be met by public uproar. In the United Kingdom, public outcry has already begun as Air Passenger Duty (billed as a green tax) has increased by up to 325 per cent in the last three years, now generating the government over two billion pounds per year at the expense of holidaymakers (Starmer-Smith, 2010). Citing his government's campaign to control excessive alcohol consumption in Norway, Johannes (Norwegian, 57) suggested that extremely high taxes are necessary to modify practices associated with strong personal benefits. 
In Norway, you have an extremely high tax on alcohol. I don't know how much effect that has on peoples' drinking. It has an effect, but if you can afford it, and you need, then you will drink. So, if it should have an effect on going by plane, I think it must be a very high tax.

The capacity for government policy alone to successfully modify excessive air travel consumption was doubted, however, as analogies were again drawn between the tobacco and tourism industries.

If someone says flying to New York is like what $\left[\mathrm{CO}_{2}\right]$ you use for four or five months [domestic living], that will be quite strong like the 'smoking kills' on the cigarette box. But people haven’t stopped smoking yet. Fewer are smoking, but people are still smoking and people will still fly. (Frode, Norwegian, 37)

As Randles and Mander (2009b, p. 95) argue, the modification of excessive air travel behaviour on a widespread scale is beyond the control of individual actors, and is networked across 'intersections between social practices, the supply and circulation of products and services; and physical technical infrastructures.' The social practices of tourism mobility are thus not only dependent on actors and modes of provision, but are also co-constituted through social norms and values (Verbeek \& Mommaas, 2008).

Consequently, broad behavioural adaptation to climate change in the context of air travel is partially dependent upon discourses that position high levels of consumption as destructive. There is no denying that a moral agenda underpins the social construction of excessive air travel as a manifestation of behavioural addiction. The emergence of a discourse of addiction surrounding air travel is the product of (and produces) changing social norms. Svein (Norwegian, 35) illustrated that while air travel may still be habitual in Norway, future consumption will likely be more constrained.

You can buy a flight from Norway to any of the big cities in Europe for 50 USD, but it's not the real cost. We can't go on like that. I think the problem will hold Norwegians back more two years from now. People are slowly changing habits.

The importance of social norms is further exemplified by William (British, 42), who doubted his family's future propensity to consume air travel if public perceptions continue to change.

Like most people, if we were made more aware of what sort of impact it [air travel] has, and we were shamed into not travelling by air, then we would never travel by air.

\section{CONCLUSION}

This article has explored the emerging position in the public press that excessive tourist air travel, or binge flying, can constitute a form of behavioural addiction (see Hill, 2007; 
Rosenthal, 2010). Framing the issue, Urry (2010, p. 93) suggests that global capitalism fuels lifestyles characterised by greater freedom to consume, and warns that excessive mobility may result in 'sites of potential mass addiction'. The present text has contributed in four important ways to understandings of how tourists are responding to the climate consequences of air travel. First, it has offered an interdisciplinary theoretical analysis of the recent social construction of 'binge flying', which hitherto has not been a subject of explicit focus in academic literature. Second, the paper has extended and deepened existing empirical work on air travel and climate change through a comparative design that has generated original findings from across two European national contexts. Third, the findings point toward a growing negative discourse surrounding frequent holiday flying, especially through the routine use of low-cost airlines for brief tourist trips. This builds upon increasing evidence of a consumer carbon conscience over air travel's climate impacts. Finally, excessive tourist air travel has been theoretically appraised and empirically supported as a site of behavioural addiction, evidenced through consistent findings amongst consumers from both Norway and the United Kingdom.

Our findings are based on a sample of largely well-educated professionals, who comprise an extremely aeromobile sub-section of their broader national populations. These individuals regularly face what the media has termed 'flyers' dilemma', in which the shortterm gratification derived from tourism's personal benefits have the potential to sit rather uncomfortably with the associated long-term climate consequences of air travel. Although our research supports previous studies that identify the various ways that air travel is embedded and networked within social lives (Larsen et al., 2007; Randles \& Mander, 2009a), the current findings highlight increasing sentiments of guilt, suppression and denial of air travel's climate impact, which span a cognitive dissonance of practice and conscience. These emergent issues of guilt, suppression and denial, alongside evidence of the difficulty inherent in modifying tourist air travel behaviour, further justify frequent holiday air travel as a behavioural addiction.

The moral agenda behind stigmatising excessive tourist air travel is explicit in the term New Puritanism. Like our participants, New Puritans are mostly well-educated and do not represent their respective societies as a whole. Practitioners and scholars must thus ask themselves how the tourism and transport industries will be transformed if, alongside climate change mitigation policies, New Puritan values, including air travel under a new 'carbon conscience' (Cohen \& Higham, 2011; Higham \& Cohen, 2011), extend farther into 'mainstream' tourist behaviour? Our evidence supports growing normative ambiguity surrounding acceptable levels of tourist air travel amidst accelerating global climate change. The tension between a growing backlash within this social group towards excessive flying and the concomitant continuation of frequent personal holiday air travel represents an open empirical question.

Continued growth in both frequent flying practices and concern over air travel's climate impacts are in a dynamic relationship and the question of whether one or the other will reach a tipping point cannot yet be determined. Self-regulation, external regulation, social 
norms, technology and physical resources will continue to co-constitute the balance. An increasing stigmatisation of 'excessive' air travel may (re)frame flying as more open to collective external mitigation. Indeed, the ways in which actors might respond to mitigation through national, and possibly global, policy was distinctly divergent between this study's Norwegian and British respondents, but lies outside the scope of the present text. These crossnational differences point to the need for additional lines of detailed comparative empirical research into how tourism consumption and responses to climate change intersect at micro and macro levels of practice.

Future research should not only seek to deconstruct the ways in which actors, modes of provision and social norms interlock to comprise tourist air travel practices, but consider various ways through which tourism can be disengaged from air travel (see for instance Dickinson et al., 2010 on the concept of 'slow tourism') and/or be re-localised through leisure and 'staycations'. Fomenting such public dialogues may further engender consumer critical appraisals of what constitutes 'legitimate holidays' versus 'dispensable' air trips (Becken, 2007, p. 362). Although the economic and social benefits of tourism to distant nation-states are still of concern and importance, there are personal benefits afforded through tourism that are also available through less-distant leisure activities, such as feelings of escape and heightened experiences of pleasure and excitement (Csikszentmihalyi, 1997, 2000), which policy-makers and governments may seek to develop and encourage.

We do not seek to mask our appraisal of frequent tourist air travel as a site of behavioural addiction as apolitical. The linkages drawn here between excessive tourist air travel and the criteria for distinguishing types of behavioural addictions are underpinned by a broader moral agenda that seeks to move tourism on to a sustainable emissions path. Nonetheless, the study's findings contribute to a wider counter-narrative, taking place in the media, the academe and sections of the public domain, in which current social norms concerning acceptable levels of tourist air travel are being challenged and subverted. Continued movement in consumer discourses towards a mainstream negative perception of the practice of holiday frequent flying may eventually find tourism consumption the further subject of query as an addictive phenomenon. Frequent air travel may then join gambling, smoking, shopping, video games and Internet use, (Clark \& Calleja, 2008), amongst others, as 'pathologised' sites of behavioural addiction that reflect society's (re)positioning of certain types of behaviour as socially dysfunctional. Elliot (1994, p. 174) notes that it is 'a feature of postmodernity that the consumption of symbolic meaning which has become central to our construction of the social world may in fact be dangerous to our social [and global] health.' A postmodern paradox for tourist air travel, therefore, is again analogous to the tobacco industry, as a social marginalisation of air travel may one day lead to consumer warnings on air transport websites, tourist brochures and in-flight safety cards that read - 'Danger: Air travel damages the planet's health'. 


\section{REFERENCES}

Barr, S., Shaw, G., Coles, T., \& Prillwitz, J. (2010). 'A holiday is a holiday': Practicing sustainability, home and away. Journal of Transport Geography, 18(3), 474-481.

Becken, S. (2004). How tourists and tourism experts perceive climate change and carbonoffsetting schemes. Journal of Sustainable Tourism, 12(4), 332-345.

Becken, S. (2007). Tourists' perception of international air travel's impact on the global climate and potential climate change policies. Journal of Sustainable Tourism, 15(4), 351-368.

Becken, S., \& Hay, J. E. (2007). Tourism and Climate Change: Risks and Opportunities. Clevedon: Channel View Publications.

Broderick, J. (2009). Voluntary carbon offsetting for air travel. In S. Gössling \& P. Upham (Eds.), Climate change and aviation: Issues, challenges and solutions (pp. 329-346). London: Earthscan.

Burns, P. (2005). Tribal tourism - cannibal tours: Tribal tourism to hidden places. In M. Novelli (Ed.), Niche tourism: Contemporary issues, trends, cases (pp. 101-110). Oxford: Elsevier.

Burns, P., \& Bibbings, L. (2009). The end of tourism? Climate change and societal challenges. 21st Century Society, 4(1), 31-51.

Cary, S. H. (2004). The tourist moment. Annals of Tourism Research, 31(1), 61-77.

Ceron, J. P., \& Dubois, G. (2007). Limits to tourism? A backcasting scenario for sustainable tourism mobility in 2050. Tourism \& Hospitality: Planning \& Development, 4(3), 191-209.

Clark, M., \& Calleja, K. (2008). Shopping addiction: A preliminary investigation among Maltese university students. Addiction Research \& Theory, 16(6), 633-649.

Cohen, S. A., \& Higham, J. E. S. (2011). Eyes wide shut? UK consumer perceptions on aviation climate impacts and travel decisions to New Zealand. Current Issues in Tourism, doi: 10.1080/13683501003653387.

Csikszentmihalyi, M. (1997). Finding flow: The psychology of engagement with everyday life. New York: BasicBooks.

Csikszentmihalyi, M. (2000). The costs and benefits of consuming. Journal of Consumer Research, 27, 267-272.

Denzin, N. K., \& Lincoln, Y. S. (2005). Introduction: The discipline and practice of qualitative research. In N. K. Denzin \& Y. S. Lincoln (Eds.), The Sage handbook of qualitative research (3rd ed.) (pp. 1-32). Thousand Oaks: Sage Publications.

Dickinson, J. (2010). Tourism and climate change - An introduction. Journal of Transport Geography, 18(3), 445-446.

Dickinson, J., Robbins, D., \& Lumsdon, L. (2010). Holiday travel discourses and climate change. Journal of Transport Geography, 18(3), 482-489.

Dubois, G., \& Ceron, J. P. (2006). Tourism/leisure greenhouse gas emission forecasts for 2050: Factors for change in France. Journal of Sustainable Tourism, 14(2), 172-191.

Elliott, R. (1994). Addictive consumption: Function and fragmentation in postmodernity. Journal of Consumer Policy, 17(2), 159-179.

Faber, R. J., O'Guinn, T. C., \& Krych, R. (1987). Compulsive consumption. In M. Wallendorf \& P. Anderson (Eds.), Advances in consumer research (Vol. 14, pp. 132-135). Provo: Association for Consumer Research. 
Fontana, A., \& Frey, J. H. (2005). The interview: From neutral space to political involvement. In N. K. Denzin \& Y. S. Lincoln (Eds.), The Sage handbook of qualitative research (3rd ed.) (pp. 695-728). Thousand Oaks: Sage Publications.

Gössling, S. (2009). Carbon neutral destinations: A conceptual analysis. Journal of Sustainable Tourism, 17(1), 17-37.

Gössling, S., Broderick, J., Upham, P., Ceron, J. P., Dubois, G., Peeters, P. \& Strasdas, W. (2007). Voluntary carbon offsetting schemes for aviation: Efficiency, credibility and sustainable tourism. Journal of Sustainable Tourism, 15(3), 223-248.

Gössling, S., \& Peeters, P. (2007). 'It does not harm the environment!' An analysis of industry discourses on tourism, air travel and the environment. Journal of Sustainable Tourism, 15(4), 402-417.

Gössling, S., \& Upham, P. (Eds.). (2009). Climate change and aviation: Issues, challenges and solutions. London: Earthscan.

Griffiths, M. (1996). Behavioural addiction: An issue for everybody? Employee Counselling Today, 8(3), 19-25.

Hares, A., Dickinson, J., \& Wilkes, K. (2010). Climate change and the air travel decisions of UK tourists. Journal of Transport Geography, 18(3), 466-473.

Higham, J. E. S., \& Cohen, S. A. (2011). Canary in the coalmine: Norwegian attitudes towards climate change and extreme long-haul air travel to Aotearoa/New Zealand. Tourism Management, 32(1), 98-105.

Hill, A. (2007, 6 May). Travel: The new tobacco, The Observer. Retrieved 13 September 2010, from http://www.guardian.co.uk/travel/2007/may/06/travelnews.climatechange

Hirschman, E. C. (1992). The consciousness of addiction: Toward a general theory of compulsive consumption. Journal of Consumer Research, 19(2), 155-179.

Høyer, K. (2000). Sustainable tourism or sustainable mobility? The Norwegian case. Journal of Sustainable Tourism, 8(2), 147-160.

Jennings, G. (2001). Tourism research. Milton: John Wiley \& Sons.

Larsen, J., Urry, J., \& Axhausen, K. (2007). Networks and tourism: Mobile social life. Annals of Tourism Research, 34(1), 244-262.

Miles, M. B., \& Huberman, A. M. (1994). Qualitative data analysis: An expanded sourcebook. Thousand Oaks: Sage Publications.

Miller, G., Rathouse, K., Scarles, C., Holmes, K., \& Tribe, J. (2010). Public understanding of sustainable tourism. Annals of Tourism Research, 37(3), 627-645.

O'Reilly, K. (2005). Ethnographic methods. London: Routledge.

Patton, M. Q. (2002). Qualitative research and evaluation methods. Thousand Oaks: Sage Publications.

Peeters, P., \& Dubois, G. (2010). Tourism travel under climate change mitigation constraints. Journal of Transport Geography, 18(3), 447-457.

Randles, S., \& Mander, S. (2009a). Practice(s) and ratchet(s): A sociological examination of frequent flying. In S. Gössling \& P. Upham (Eds.), Climate change and aviation: Issues, challenges and solutions (pp. 245-271). London: Earthscan.

Randles, S., \& Mander, S. (2009b). Aviation, consumption and the climate change debate: 'Are you going to tell me off for flying?'. Technology Analysis \& Strategic Management, 21(1), 93-113.

Reckwitz, A. (2002). Toward a theory of social practices: A development in culturalist theorizing. European Journal of Social Theory, 5(2), 243.

Rojek, C. (1993). Ways of escape: Modern transformations in leisure and travel. Houndmills: MacMillan Press. 
Rosenthal, E. (2010, 24 May). Can we kick our addiction to flying? Guardian. Retrieved 13 September 2010, from http://www.guardian.co.uk/environment/2010/may/24/kickaddiction-flying

Ryan, C. (2010). Ways of conceptualizing the tourist experience: A review of literature. Tourism Recreation Research, 35(1), 37-46.

Shaw, S., \& Thomas, C. (2006). Discussion note: Social and cultural dimensions of air travel demand: Hyper-mobility in the UK? Journal of Sustainable Tourism, 14(2), 209-215.

Siegle, L. (2005, 23 October). Just say 'no'. The Observer. Retrieved 11 July 2010, from http://www.guardian.co.uk/lifeandstyle/2005/oct/23/ethicalliving

Smith, I. J., \& Rodger, C. J. (2009). Carbon offsets for aviation-generated emissions due to international travel to and from New Zealand. Energy Policy, 37(9), 3438-3447.

Starmer-Smith (2010, 24 March). Budget 2010: Air Passenger Duty and the rising cost of flying for British families. The Telegraph. Retrieved 13 September 2010, from http://www.telegraph.co.uk/travel/travelnews/air-passenger-duty/7513091/Budget2010-Air-Passenger-Duty-and-the-rising-cost-of-flying-for-British-families.html

Stoll-Kleemann, S., O'Riordan, T., \& Jaeger, C.C. (2001). The psychology of denial concerning climate change mitigation measures: Evidence from Swiss focus groups. Global Environmental Change, 11(2), 107-117.

Urry, J. (2002). Mobility and proximity. Sociology, 36(2), 255-274.

Urry, J. (2010). Sociology and climate change. The Sociological Review, 57(2), 84-100.

Verbeek, D. \& Mommaas, H. (2008). Transitions to sustainable tourism mobility: The social practices approach. Journal of Sustainable Tourism, 16(6), 629 - 644.

Walker, A. L., \& Lidz, C. W. (1983). Common features of troublesome habitual behaviours. In P. K. Levison, D. R. Gerstein \& D. R. Maloff (Eds.), Commonalities in substance abuse and habitual behaviour (pp. 29-44). Lexington, MA: Lexington Books.

Warde, A. (2005). Consumption and theories of practice. Journal of Consumer Culture, 5(2), 131. 